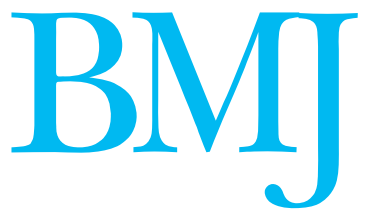

\title{
China's one child policy
}

\author{
The policy that changed the world
}

$\overline{\text { Research p 371 }}$

The Chinese one child policy is unique in the history of the world. It was a source of great pain for one generation, but a generation later it began to yield important economic benefits. For China, and the world as a whole, the one child policy was one of the most important social policies ever implemented.

Rapid population growth is an unforgiving task master. Even with the one child policy-as a result of the high birth rate a generation before-China still has one million more births than deaths every five weeks. The Chinese State Council launched the policy in 1979, "so the rate of population growth may be brought under control as soon as possible." However, the root cause of the policy lay back in the 1960s with Mao Zedong's belief that "the more people, the stronger we are"-an ideology that prevented China from developing the highly successful voluntary family planning programmes that countries such as South Korea and Taiwan had put in place in the 1960s. ${ }^{1}$

Deng Xiao-ping, the acknowledged architect of China's contemporary economic miracle, was a major sponsor of the 1979 policy. He said that unless the birth rate fell rapidly, "we will not be able to develop our economy, and raise the living standards of our people." Economists and demographers now recognise that a falling birth rate offers a demographic dividend, as the economically productive proportion of the population grows more rapidly than the general population. ${ }^{34}$ Without a rapid decline in fertility, China's economy would not have grown by $7-8 \%$ a year over the past decade; such growth has lifted an unprecedented 150 million people out of abject poverty.

Could China ever have achieved the same results without the one child policy? Possibly. Between 1952 and 1979, the Chinese total fertility rate fell from 6.5 to 2.75 , and today all age groups and social classes prefer to have two children or fewer. ${ }^{5}$ Some western commentators believe China over-reacted, ${ }^{6}$ whereas others emphasise that even small changes in the timing of a decline in fertility are important. The difference between a total fertility rate of 2.1 , which might have been achieved without the policy, and a total fertility rate of 1.6 (found today) releases $24 \%$ more resources for the family and national investment. The Indian economy has begun to grow rapidly, but unlike China the decline in fertility has been uneven, and states such as Bihar and Uttar Pradesh (total fertility rates of 4.4
As well as its effect on fertility rates, China's one child policy has had a variety of other effects. Each successive birth cohort is smaller and women tend to marry men who are several years older than themselves, so fewer potential brides are available than grooms. Further, like many countries, China has a long tradition of favouring boys and the technology of ultrasound and selective abortion, although illegal, has further skewed the sex ratio. The under-registration of female births and higher mortality due to greater neglect of female babies makes exact measurement difficult, but Ding and Hesketh found a ratio of male to female births of 1.15 across the whole cohort and of 1.23 for first births between 1996 and 2001. ${ }^{5}$ Lastly, when birth rates fall rapidly, during their most productive years the younger generation needs to support a high ratio of old people, ${ }^{7}$ although as people age they may also save at a higher rate. ${ }^{8}$ China's new prosperity has repercussions around the world in other ways-for instance, Chinese competition for oil is one reason that the cost of petrol is so high.

Undoubtedly, the one child policy caused great individual pain and it has been heavily criticised. For people in the United States especially, the idea that society's long term interests could ever be more important than individual rights was anathema. A veritable media industry has arisen in the US criticising the one child policy, although it chooses to overlook the tens of millions of coercive pregnancies in other countries where family planning and legal abortion are not available. The Bush administration refuses to fund the United Nations Population Fund because it works in China, even though this fund has never supported the one child policy.

The Chinese demographic crisis arose because between 1960 and 1973 the population grew by $2 \%$ or more each year. Today, the whole of sub-Saharan Africa, along with Pakistan, Iraq, Afghanistan, and the Philippines, have population growth rates of at least $2 \%$. Between now and 2050 the population of Niger, West Africa, is projected to grow fivefold from 14 to 53 million. As the World Bank acknowledges, ${ }^{9}$ without a rapid decline in fertility, tens of millions of Nigeriens will be uneducated, unemployed, and desperately poor; they will either starve or be fed by Western humanitarian aid.

Last month, the UK All Party Parliamentary Group on Population, Development, and Reproductive Health ended an important series of hearings on the impact of population growth on the millennium development 
goals. Experts from around the world called on the UK's Department for International Development and the international community to give much greater emphasis to population and family planning. Baige Zhao, vice minister of the National Population and Family Planning Commission of China offered "to share our information and also our commodities."10 As China reaches out to help other countries, their contribution to international family planning could prove an important additional global benefit of the sacrifices the Chinese people made to implement the one child policy.

\section{Malcolm Potts Fred H Bixby endowed chair}

(potts@berkeley.edu)

School of Public Health, University of California, Berkeley, CA 94720-7360, USA

Competing interests: None declared.

1 Potts M. Sex and the birth rate: human biology, demographic change and access to fertility regulation methods. Popul Dev Rev 1997;23:1-40.
2 Chen P-C. Rural health and birth planning in China. North Carolina: International Fertility Regulation Program, 1981.

3 Birdsall N, Kelly A, Sinding SW. Population matters: demographic change, economic growth and poverty in the developing world. Oxford: Oxford University Press, 2001.

4 Feng W, Mason A. Demographic dividend and prospects for economic development in China. United Nations Expert Group on Social and Economic Implications of Changing Population Age Structure, UN/POP/PD/ 2005/5, 2005.

5 Ding QJ, Hesketh T. Family size, fertility preferences, and sex ratio in China in the era of the one child family policy: results from national family planning and reproductive health survey. BMJ 2006;333:371-3.

6 Greenhalgh S. Science, modernity, and the making of the one-child policy. Popul Dev Rev 2003;29:163-96.

7 Zimmer Z, Kwong J. Family size and support of older adults in urban and rural China: current effects and future implications. Demography 2003;40:23-44.

8 Hesketh T, Xing ZW. The effect of China's one-child family policy after 25 years. N Engl J Med 2005;353:1171-6.

9 World Bank. Niger: providing all Nigeriens with food, education and health care; a demographic perspective. World Bank report 34219-NE, 2005.

10 All Party Parliamentary Group on Population, Development and Reproductive Health. 2006 hearings: oral evidence, hearing 4. www.appgpopdevrh.org.uk/Publications/Population $\% 20$ Hearings/

Population\%20Hearings.htm (last accessed 3 Aug 2006).

doi 10.1136/bmj.38938.412593.80

\section{Overweight and obesity in China}

\section{The once lean giant has a weight problem that is increasing rapidly}

$\mathrm{A}$ bout one fifth of the one billion overweight or obese people in the world are Chinese. China was once considered to have one of the leanest populations, ${ }^{1}$ but it is fast catching up with the West in terms of the prevalence of overweight and obesity; disturbingly, this transition has occurred in a remarkably short time. ${ }^{2}$

Data from the 2002 national nutrition and health survey showed that $14.7 \%$ of Chinese were overweight (body mass index $\left(\mathrm{BMI} ; \mathrm{kg} / \mathrm{m}^{2}\right) \geq 25$ ) and another $2.6 \%$ were obese $(\mathrm{BMI} \geq 30)$, such that there are currently (2002) 184 million overweight people, and a further 31 million obese people, in China, out of a total population of 1.3 billion (table). ${ }^{3}$ Although the prevalence of obesity in China is relatively low compared with Western countries such as the United States, where over half of adults are either overweight or obese, it is the rapid increase of the condition, ${ }^{4}$ especially among children, that is particularly alarming. Data from the China national surveys on the constitution and health in school children showed that the prevalence of overweight and obesity in children aged 7-18 years increased 28 times and obesity increased four times between 1985 and 2000 (figure), ${ }^{5}$ a trend that was particularly marked in boys.

Increasing evidence indicates that the World Health Organization's definitions of overweight (BMI $>25)$ and obesity (BMI >30) may underestimate the true burden of the condition. These cut points are derived from white populations and hence may not be applicable to Asians. On the basis of a meta-analysis of associations of BMI with risk factors for cardiovascular disease among 240000 Chinese adults, and of the longitudinal relationships of BMI to cardiovascular events in 76000 participants, the Working Group on Obesity in China has recommended that a BMI of 18.5 to 23.9 should be considered as optimal, 24.0 to 27.9 as overweight, and 28.0 and above as obese. ${ }^{67}$ These rec- ommendations have been used in the guidelines for prevention and control of overweight and obesity in Chinese adults. ${ }^{8}$ Using these cut points rather than the WHO definitions would increase the prevalence of overweight and obesity in China by a further 66 million, to over a quarter of a billion people (table). More informative measures of obesity, such as waist circumference or waist:hip ratio, are considered to be more strongly correlated with cardiovascular risk and may be more appropriate for use in Asian populations, in whom central adiposity has been shown to occur at lower levels of BMI than in white people.

The explanations of China's recent epidemic of overweight and obesity include changes to the traditional diet, reduced levels of physical activity, and increased sedentary lifestyles. Recent data from the national surveys of nutrition indicate noticeable

BMJ 2006;333:362-3

Prevalence of overweight and obesity in national nutrition and health survey 2002 and estimated number of overweight and obese people in China

\begin{tabular}{|c|c|c|c|c|c|c|c|}
\hline \multirow[b]{2}{*}{$\begin{array}{l}\text { Age } \\
\text { group }\end{array}$} & \multirow[b]{2}{*}{$\begin{array}{c}\text { No } \\
\text { surveyed }\end{array}$} & \multicolumn{3}{|c|}{ Prevalence $(\%)^{*}$} & \multicolumn{3}{|c|}{ Estimated No (million)† } \\
\hline & & Overweight & Obesity & $\begin{array}{l}\text { Overweight } \\
\text { and obesity }\end{array}$ & Overweight & Obesity & $\begin{array}{l}\text { Overweight } \\
\text { and obesity }\end{array}$ \\
\hline \multicolumn{8}{|c|}{ China criteriał } \\
\hline $0-6$ & 24947 & 3.4 & 2.0 & 5.4 & 4 & 2 & 6 \\
\hline $7-17$ & 44880 & 4.5 & 2.1 & 6.6 & 10 & 5 & 15 \\
\hline$\geq 18$ & 140022 & 22.8 & 7.1 & 29.9 & 200 & 60 & 260 \\
\hline Total & 209849 & 17.6 & 5.6 & 23.2 & 214 & 67 & 281 \\
\hline \multicolumn{8}{|c|}{ WHO criteria§ } \\
\hline $0-7$ & 24947 & 3.4 & 2.0 & 5.4 & 4 & 2 & 6 \\
\hline 7-17 & 44880 & 4.2 & 1.8 & 6.0 & 10 & 4 & 14 \\
\hline$\geq 18$ & 140022 & 18.9 & 2.9 & 21.8 & 170 & 25 & 195 \\
\hline Total & 209849 & 14.7 & 2.6 & 17.3 & 184 & 31 & 215 \\
\hline
\end{tabular}

${ }^{*}$ Standardised by age and social economic status according to 2000 national census. †Population in 2000 census $\times$ prevalence.

ҒAge 0-6, as WHO criteria; age 7-17: overweight BMI $\geq 85$ th centile, Working Group on Obesity in China, obesity BMI 295 th centile; age 18 and over: overweight BMI 24-<28, obesity BMI $\geq 28$.

$\S$ Age $<7$ years: overweight $2<$ WHO Z score $\leq 3$, obesity WHO Z score $>3$; age $7-17$ : overweight $B M I \geq 85$ th

WHO centile, obesity BMI $\geq 95$ th centile; age 18 and over: overweight BMI $25-<30$, obesity BMI $\geq 30$. 